\title{
Fine Characterization Method for Interlayers in Complex Meander River Sandstone Reservoir: A Case Study of Um7 Sand of C Oilfield in Bohai Bay Area
}

\author{
Jingmin Guo, Wei Wang, Jie Tan, Qin Peng, Dong Zhang \\ Bohai Oilfield Research Institute of CNOOC Ltd., Tianjin Branch, Tianjin, China \\ Email: guojm6@cnooc.com.cn
}

How to cite this paper: Guo, J.M., Wang, W., Tan, J., Peng, Q. and Zhang, D. (2019) Fine Characterization Method for Interlayers in Complex Meander River Sandstone Reservoir: A Case Study of Um7 Sand of C Oilfield in Bohai Bay Area. International Journal of Geosciences, 10, 405-418. https://doi.org/10.4236/ijg.2019.104023

Received: April 2, 2019

Accepted: April 20, 2019

Published: April 23, 2019

Copyright $\odot 2019$ by author(s) and Scientific Research Publishing Inc. This work is licensed under the Creative Commons Attribution International License (CC BY 4.0).

http://creativecommons.org/licenses/by/4.0/

\begin{abstract}
Taking the Um7 meandering river complex sandstone reservoir of Bohai Bay $\mathrm{C}$ oilfield as an example, the interlayer type is defined according to the interlayer lithology and sedimentary genesis, and the identification mode of different types of interlayer is established, and the interlayer comparison of the whole area is carried out by using this mode. The results show that the interlayer can be further defined as the stable distributed interlayer and the randomly distributed interlayer according to the morphology of the interlayer. The distribution characteristics of the two types of interlayers are characterized by the well-to-well comparison method and the data analysis method, and the three-dimensional characterization is carried out. The results more closely reflect the spatial distribution of the interlayer, but also are closer to the underground real situation.
\end{abstract}

\section{Keywords}

Meander River Reservoir, Interlayer, Fine Characterization, Horizontal Well Development

\section{Introduction}

Interlayer is one of the main reasons for the heterogeneity of fluid flow in continental reservoirs [1] [2] [3] [4] [5]. The distribution characteristics of interlayers have a great influence on the development of sand bodies [6] [7] [8] [9], especially in bottom water reservoir. In the reservoir, the effect of suppressing the bottom water coning through the interlayer has obvious effect [10] [11]. The predecessors have done a lot of research on the characterization of the internal 
interlayer of different continental reservoirs. The characteristics of various interlayers and the influence on oil-water migration have been discussed according to the lithology classification from the perspective of lithology by Yan Yaozu etc. [7] [12] [13] [14]. According to the classification of sedimentary origin, the dissections have been discussed from the perspective of origin mechanism by Liu Chengzhi, Wang Jian, etc. [15] [16]. The different types of interlayer have been divided according to the distribution characteristics and stability of the interlayer and finely characterized for all kinds of interlayers by Wang Yanzhong, Zhang Shangfeng, Zhang Guoyi, etc. [17] [18] [19]. According to the position and physical property of the interlayer in the sand body unit, Zhao Hanqing divided the types of interlayer and described the characteristics of each kind of interlayer [20]. Different methods of study are combined with the characteristics of respective reservoirs and interlayers.

The Um7 sand body of $\mathrm{C}$ oilfield is a meandering river composite sand body, which is a river filling body composed of multiple single rivers of different stages. The single sand channels inside the composite sand body are cut and stacked and the distribution characteristics of the interlayer are complex. According to lithology, it is divided into argillaceous interlayer, calcareous interlayer, and physical interlayer composed of poor physical sandstone or argillaceous sandstone. Because of the rareness of the calcareous interlayer and physical interlayer, there is no description of the two types of interlayer. While in the underground reservoir, the two types of interlayers are often spliced with the mudstone interlayer to form an interlayer of contiguous distribution. The previous studies about the mudstone interlayer only depict the stable distribution of the interlayer. The smaller and scattered interlayers are not been characterized sufficiently. According to the actual production status, when the frequency and density of the scattered interlayers in the reservoir are large, the production of the wells in the reservoir will be significantly affected. In the past modeling work, only the continuously distributed interlayers were described in three-dimensional characterization and a large number of discontinuous and scattered small interlayers were not been described.

Combined with the production status of production wells, the characteristics of interlayers in the reservoir are analyzed in this paper. It is considered that the distribution pattern of the interlayer is the most direct factor affecting the fluid migration in the reservoir. Based on the conventional research, the type of interlayer is further determined according to its shape, which is divided into the stable distribution interlayer and the random distribution interlayer. Different methods are used for three-dimensional characterization of interlayer with different distribution types. According to the characteristics of interlayer distribution, interactive method and stochastic simulation method are used for three-dimensional modeling of the research results. The final results are verified by reservoir numerical simulation, and the fitting effect is good. This study improves the accuracy of the interlayer characterization and makes up for the deficiencies in previous research and modeling. 


\section{Oilfield Overview}

The $\mathrm{C}$ oilfield is located in the $\mathrm{S}$ bulge in the Bohai Bay. The M Formation in the Minghuazhen sand set is the main oil-bearing strata of the oilfield. The sedimentary type is mainly composed of the meandering river sediment, and multiple sets of composite channel sand bodies are developed inside the M Formation. The sand body of the M Formation has good continuity and thick thickness. The oil-bearing area and sand body distribution are controlled by structure and lithology. It is a typical lithologic structural reservoir. The physical properties of the reservoir are characterized by high porosity and high permeability, with an average permeability of $2600 \mathrm{mD}$ and an average porosity of $32.7 \%$. The bottom water of the $\mathrm{M}$ Formation is large in scale, and the bottom water energy is sufficient. Moreover, most of the sand body has poor crude oil properties, and the viscosity of the target sand body Um7 formation is $350 \mathrm{mPa}$.s.

Most of the single sand bodies in the $M$ Formation are strong bottom water reservoirs, and Um7 sand body is one of them. The bottom water cone is the main problem in this type of oil reservoir. In the development process, the horizontal wells are mainly used, which has achieved good results. In the reservoir, the size, shape, thickness and relative position of the interlayer will have a certain impact on the seepage mode of the horizontal well. The horizontal well can be deployed in combination with the interlayer distribution, which is good to improve oil recovery [10] [11]. While conventional interlayer studies lack a quantitative description of the spatial distribution characteristics of the interlayer, the characterization of the interwell stable interlayer is too continuous or lacks a description of the discontinuous interlayer distribution. In this paper, the sand body Um7 is taken as an example. The distribution characteristics of different interlayers are characterized by the well-to-well comparison method and the data analysis method. Through the integrated research of geological modeling, the results of the interlayer research are quantitatively mapped into the $3 \mathrm{D}$ geological model. A new idea for the quantitative characterization of the interlayer is proposed.

\section{Division and Identification of the Interlayer}

The division of the interlayer type is the key to the study of the interlayer. According to the division, the distribution range of different types of interlayers is further characterized, so that a deeper understanding of the interlayer distribution can be obtained. At present, the main classification methods are divided according to sedimentary genesis, lithology, sedimentary period and morphology, etc. The paper studies the lithology and sedimentation genesis. According to the research results, the internal interlayer of Um7 sand was determined as two types of stable distribution interlayer and random distribution interlayer

\subsection{Classification and Identification of Interlayer Types by Lithology}

The interlayer lithology in the Um7 sand body is mainly mudstone, which is a 
non-permeable layer in the reservoir that can prevent or control the fluid surge. The main reason for the formation of the interlayer is the increase of muddy or calcium content in the reservoir or the thinning of the rock particles, or the local physical properties of the reservoir are deteriorated. Using the core calibration logging data, the logging phase corresponding to different lithologies can be identified. The interlayer of Um7 sand is classified into three types: argillaceous interlayer, calcareous interlayer and physical interlayer.

The main lithology of calcareous interlayer is calcium-bearing sandstone and calcareous sandstone, which is mainly due to the carbonate cementation and uneven dissolution of sediments. The calcium from mudstone is often cemented near the bottom and top of the reservoir and near the mud masses in the reservoir, causing calcium layers to form in coarse sandstone. The logging phase characteristics of the interlayer are: the density curve and the resistance curve are both abnormally high, showing a peak shape, and the neutron curve is low value, as shown in Figure 1. Calcium interlayers are more randomly distributed in the Um7 sand body, the frequency of drilling in the well is lower, and the plane continuity is extremely poor.

The main lithology of the argillaceous interlayer is mudstone and silty mudstone, which is the main type of Um7 sandbody interlayer, mainly sedimentary products. The characteristics of the electrical measurement curve are "two high and one low": high gamma value and density curve value, low resistance value, as shown in Figure 1. The thickness and extent of the mudstone interlayer vary according to the type of deposition, and can be further divided in the sedimentary cause division.

The physical interlayer is a non-permeability layer in the sandstone that does not reach the lower limit of reservoir physical properties, such as argillaceous siltstone with higher shale content, or poorly classified pebbly sandstone, which is characterized by a natural gamma curve smaller than the baseline and resistance. The curve value is low and the porosity and permeability is lower than the lower limit of reservoir physical properties, as shown in Figure 1. The interlayer distribution is unstable and the continuity between wells is poor [19].

According to the interlayer drilling situation, the calcareous, argillaceous and physical interlayers account for $1 \%, 92 \%$ and $7 \%$ respectively. The proportion of calcareous interlayer and physical interlayer is small, and the distribution is relatively random. The interlayer in the sand body is mainly the muddy interlayer.

\subsection{Dividing and Identifying Interlayer Types by Deposition Causes}

Through the identification and statistics of the well logging on the well that meets the Um7 sand body, the mudstone accounts for $92 \%$ of all interlayers. According to the sedimentary origin, the mudstone interlayer can be further divided into: side interlayer in the point bar, floodplain mudstone and others sedimentary mudstone. 
C1

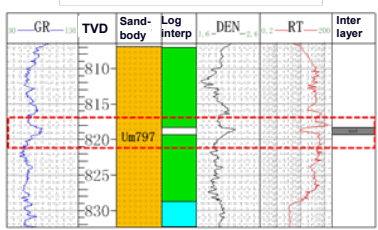

Argillaceous Interlayer
C2

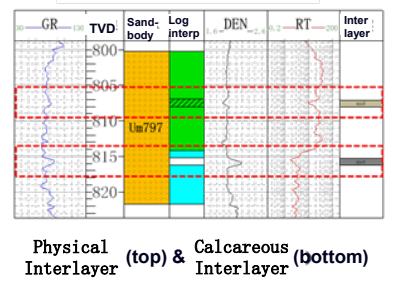

C3

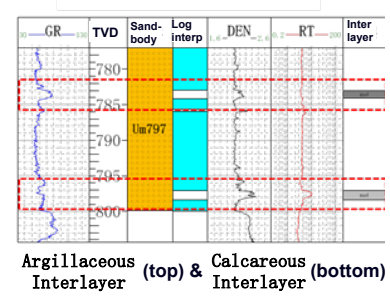

Figure 1. Electric logging characteristics of three kinds of interlayers.

According to the single-well phase rock electric identification, side interlayer in the point bar is characterized by: according to the core, the side interlayer in the point bar are thinner, generally about $30 \mathrm{~cm}$, corresponding to the log response, the gamma curve is spike-like or finger-like. Part of the side interlayer in the point bar is affected by the surrounding rock; the amplitude of the electrical measurement curve is low; the resistance curve is generally between the mudstone and the siltstone. On the plane, according to the empirical formula proposed by Leeder, $\mathrm{Wu}$ Shenghe et al. [21], the logging curve is used to calculate the characteristic statistical river channel height, and the inner side layer of the Um7 sand body is calculated to be within $0.2 \mathrm{~km}^{2}$.

The characteristics of the floodplain mudstone are: on the core, the mudstone is mostly yellow-brown and other oxidized colors, and also weakly reduced colors such as gray-green. The thickness of mudstone varies greatly, generally around $2 \mathrm{~m}$. The thickness of a few large-scale floodplains can reach more than 5 $\mathrm{m}$. The lateral product response is characterized by an abnormally high gamma curve, an abnormally low resistance curve, and a peak shape or flat jagged [3], as shown in Figure 2.

In addition to the above two types of mudstone interlayers, the sand body also includes abandoned river mudstones, mudstones deposited in the later stages of river channel formation during flood periods, etc. The main characteristics of the logging phase are that the top mudstone is relatively pure and the gamma curve is jagged high value, the lower part is gradually changed to silty mudstone and argillaceous siltstone, and the gamma curve amplitude column gradually becomes lower. This type of interlayer is often distributed in a strip shape with a small occlusion range.

According to the well logging identification and statistics in the well, the mudstone interlayer of the floodplain in the Um7 sand body accounts for 70\% of the total mudstone interlayer, the lateral sedimentary mudstone accounts for $25 \%$, and the other type of interlayer accounts for $5 \%$.

The floodplain mudstone has the characteristics of thicker thickness and wider distribution, but the proportion of the mudstone interlayer which is stable in the composite channel sand body in the actual underground reservoir is small. According to the statistics of the 13 meandering river outcrop sections by American scholar G. A. Zeito, The stable mudstone layer over $150 \mathrm{~m}$ only accounts for $17.3 \%$ [20], because most of the mudstone layers will be destroyed by 


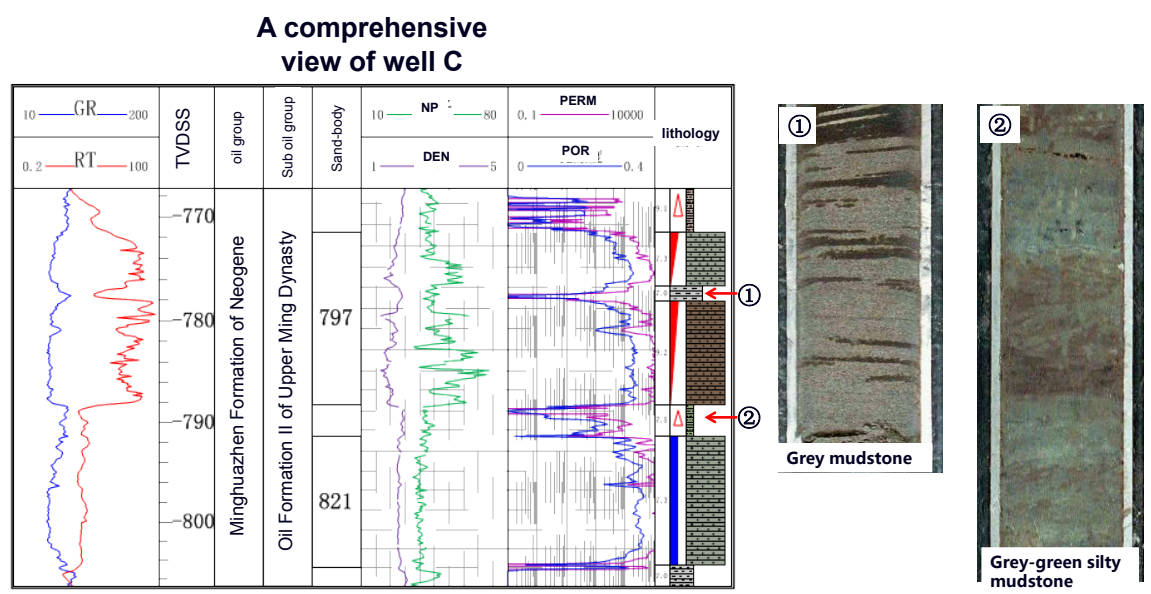

Figure 2. Core features for flood plain mudstone.

river channel cutting in the later stage. According to the comparison of the wells, the stable distribution of the interlayers in the Um7 sand body accounts for all the interlayers. $19 \%$, the remaining interlayers are mostly interlayers with a small distribution [22], which include calcareous interlayers, physical interlayers and mudstone interlayers such as floodplain mudstones and lateral layers after river erosion, and interlayer combinations composed of discontinuous interlayers. The development of horizontal wells has a certain influence. Therefore, the type of interlayer is divided according to the extent of interlayer distribution: the stable distribution interlayer and random distribution interlayer, as shown in Figure 3. According to the characteristics of the two types of interlayers, different methods are used to describe [23].

\section{Characterization of Interlayer Spatial Distribution}

By combining lithology, electrical and physical characteristics, the logging facies of different types of interlayers are identified from a single well, and the mudstone interlayer of the floodplain are laterally compared to find a floodplain with a wide range of distribution, thus depicting the stable distribution interlayer. For the instable distribution of the interlayer, the Petrel software is introduced for data analysis, and the spatial distribution law of the random distribution interlayer is obtained.

\subsection{Description Method of Stable Distribution Interlayer}

According to the above research, in the composite channel sand body Um7, interlayer with stable distribution are mainly flood plain mudstones, which is characterized by thicker thickness and good continuity, and can be compared and tracked within a certain range.

Guided by modern sediments, combined with the predecessors' exposition of the river's outcrop profile, the flooding deposits in the meandering river reservoir are mainly deposited in the flood period. During the flood period, the flood overflows the river, and the fine particles carried by the water flow are widely 


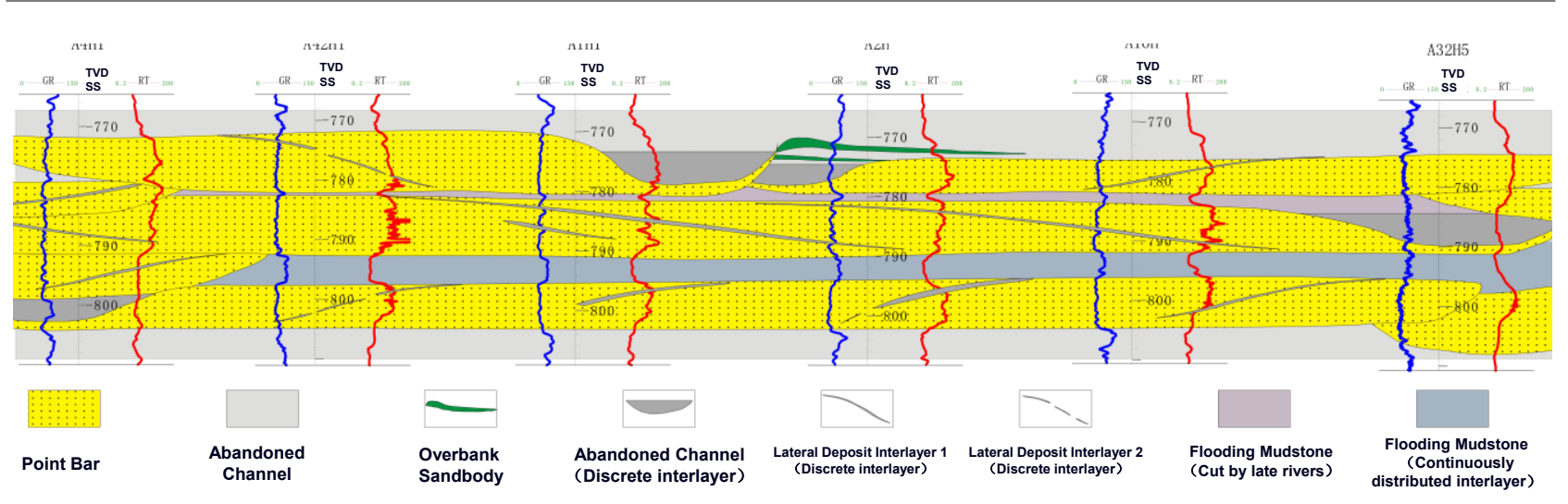

Figure 3. The pattern for the stable-distribution interlayers and the random-distribution interlayers.

distributed on both sides of the river. In some large flood events, the flood overflow during the flood period floods both sides of the river bank. During the flooding period, the river water drops to low speed, the fine-grained sediments carried by the flood are deposited from the suspended state and covered on the early sediments, forming the sequence of lower sandstone, upper siltstone and mudstone at some locations. Frequent flood events lead to an increase in the thickness of flooded mudstone.

When the flooded mudstone layer is completely preserved, a stable distributed interlayer is formed, which is mainly affected by the elevation of the reference plane of the stratum. The datum plane rises and the accommodation space can be increased continuously. The late flood erosion ability is weak, which is conducive to the formation of stable distributed interlayer; if the datum is lowered, the accommodation space will be reduced. The late flood will have a stronger effect on the early sediment erosion, and the flooded mudstone will be eroded to form a random distribution interlayer. According to the spatial distribution characteristics of the floodplain mudstone, the continuous interlayer was characterized.

Firstly, the flooded mudstone with a wide distribution of the target sand body is selected as the marker layer, and the isochronous sedimentary leveling is carried out according to the marker layer. According to the morphological characteristics of the near-level development of the flooding sediment, the interlayer with similar characteristic curves at the same elevation is tracked and sieved. The interlayer with the extension distance above 3 wells is detected, and the flat section is used for tracking. The sand body is rotated and compared under the layer leveling. According to the overlapping relationship and contact relationship of the sand body, the distribution of the interlayer between the sand bodies is indirectly described.

Secondly, the combination of the curved shape formed by the shape of the interlayer curve and the curved shape of the upper and lower sandstones is used as a basis for determining whether the interlayer between adjacent wells belongs to the same set or the same period. In the 90-degree phase-shift seismic section, the thickness of the interlayer of about $3 \mathrm{~m}$ and thicker has a certain reaction, which 
is characterized by a set of weak reflection events interlayered between the two sets of strong reflection events, as shown in Figure 4, using the combination of well and seismic, in the seismic section. Tracking and characterization can be performed to obtain a range of interlayers having a thickness of $3 \mathrm{~m}$ or more.

Nine sets of stable distribution interlayers were characterized by the above method. The results show that on the plane, the Um7 sand body has a regular distribution of stable distribution interlayer, which is more frequent in the middle part of the sand body. The interlayer is mainly concentrated in the middle and upper part of the sand body, and most of them develop at the interface position of the four-level structure. In response to the smaller scale of the river, the floodplain increased. Morphologically, the results of continuous well tracking show that the shape of the stable distribution interlayer is mostly irregular. In the range, due to the cutting action of the later river channel, the distribution range of the stable distribution type interlayer is less than $1 \mathrm{~km}^{2}$, and the range is between 0.3 and $0.9 \mathrm{~km}^{2}$. In the vertical direction, the overall average thickness of the continuous interlayer is about $1.5 \mathrm{~m}$, and the thickness of some interlayers is thicker, which can reach more than $6 \mathrm{~m}$. However, the thicker mudstone area appears only in the interlayer, and the overall thickness of the stable distribution type interlayer is less than $3 \mathrm{~m}$.

\subsection{Description Method of Random Distribution Interlayer}

The randomly distributed interlayer mainly includes flooded mudstones and side interlayers within $0.2 \mathrm{~km}^{2}$, and randomly distributed non-mudstone interlayers. The continuity is relatively poor, but when the random distribution interlayer distribution frequency is high, the development effect of horizontal wells is Certainly affected. Attempts to statistically analyze the distribution law of the random distribution type interlayer, and find the distribution function of the random distribution interlayer which is the most consistent with the underground reality.

The data analysis method mainly uses the variogram analysis method for the study of the distribution characteristics of the interlayer. Firstly, according to the well spacing statistics, the most reasonable step size is obtained. According to the statistics of 100 pairs of well samples, the most reasonable step size of the study area is $50 \mathrm{~m}$, as shown in Figure 5. On this basis, reasonable bandwidth and tolerance angle are selected. The tolerance angle is $45^{\circ}$, and the search interval is 30 degrees, and the maximum main range distance and direction of each layer are obtained by searching in various directions, as shown in Figure 6.

According to the statistics, there are some differences in the parameters between the layers, but the overall distribution characteristics are similar. The main range of the main range is the northeast-southwest direction, which is consistent with the provenance orientation. The main range is between $300 \mathrm{~m}$ and $400 \mathrm{~m}$. The secondary range is between 150 and $240 \mathrm{~m}$, and the vertical range is $3 \mathrm{~m}$ [14]. 


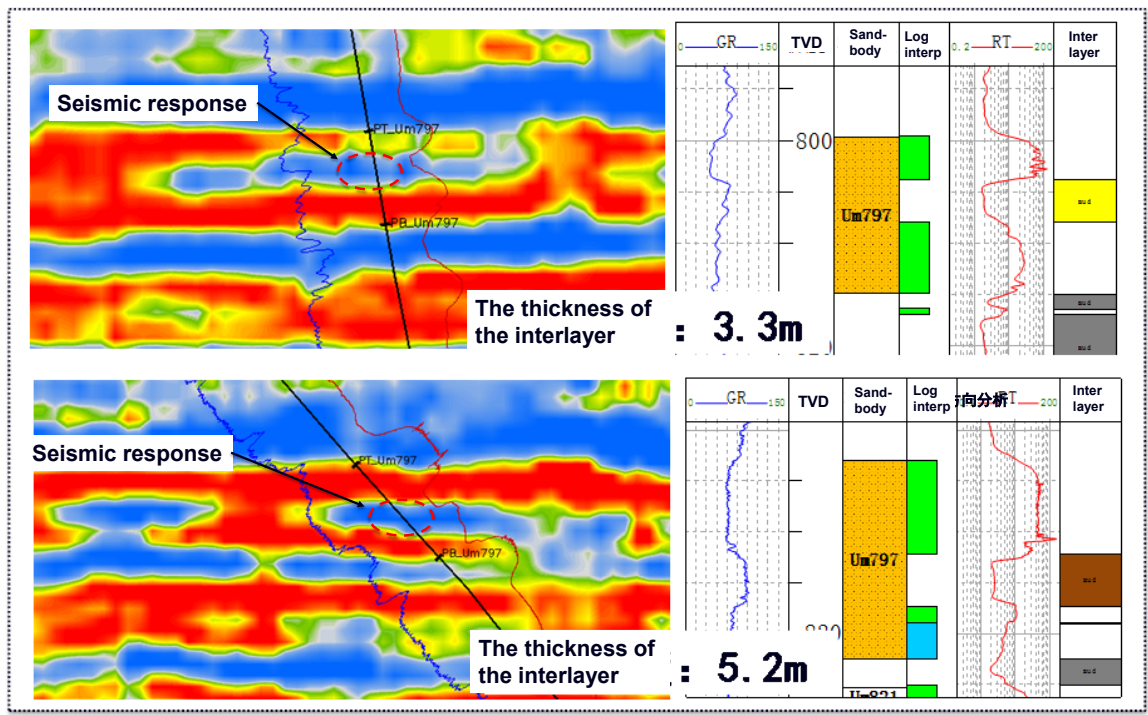

Figure 4. Uses well \& seismic combination to depicted the stable-distribution interlayers.

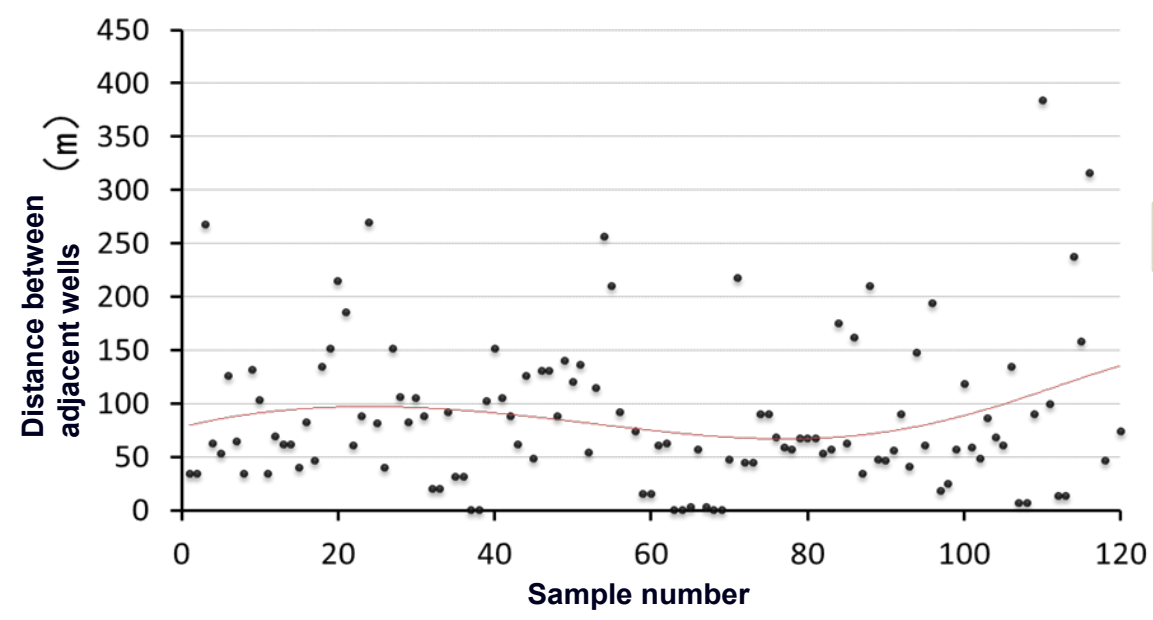

Figure 5. Determination of the most reasonable step for the variogram.

\subsection{Three-Dimensional Characterization of Interlayer}

According to the analysis of the interlayer characteristics, the distribution characteristics of the stable distribution interlayer and the random distribution interlayer are obtained. For the stable interlayer, an interactive characterization method is adopted, and the random interlayer is characterized by a random simulation method.

By the optimization of the modeling method, the simulation of the randomly distributed interlayer selects the sequential indication method. The flooded mudstones are scattered after being damaged by the later river channel, while the other non-mudstone interlayers are poor in continuity and random in distribution. The sequential indication method has certain advantages in simulating irregular shapes. Combined with the results of data analysis, the spatial distribution characteristics of randomly distributed interlayers can be well characterized [19] [23] [24] [25], as shown in Figure 7. 

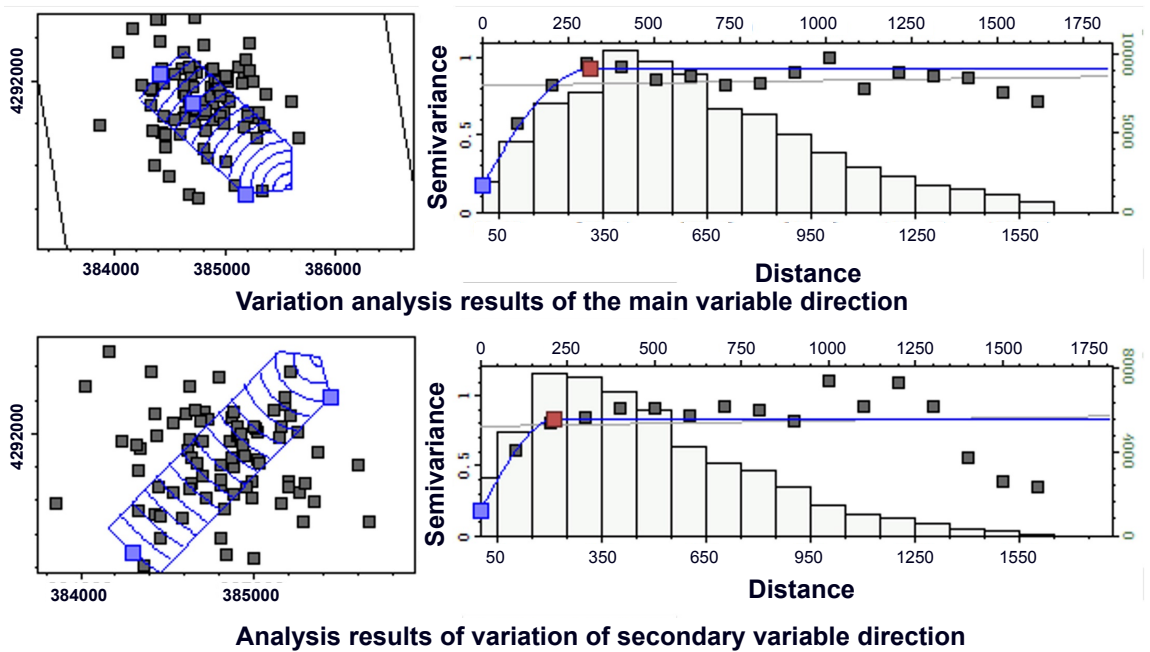

Figure 6. The analysis result of major range and minor range of Um7-1.

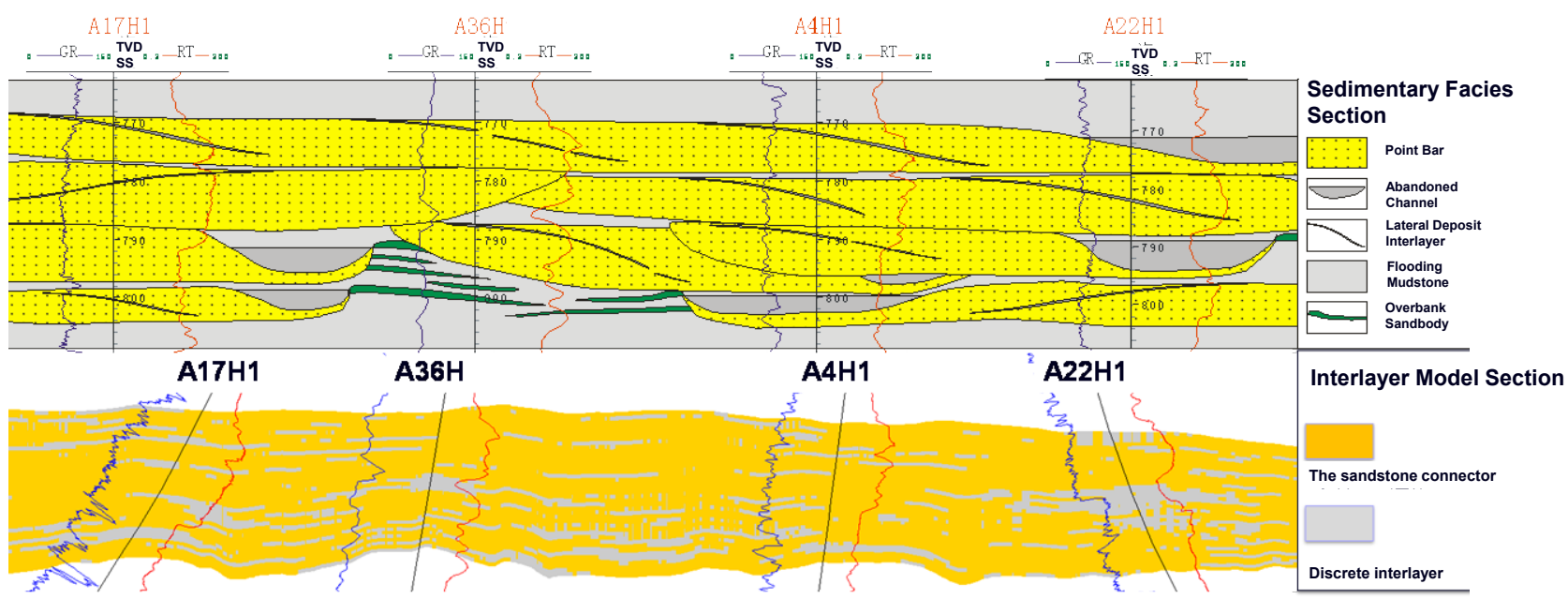

Figure 7. Comparison of interlayer simulation results (bottom) with microfacies profile (top).

In the stochastic simulation, the characteristics of the stable distribution type interlayer cannot fully conform to the characterization results of the geological personnel. Reference sedimentary profile, using the interactive method, the stable distribution type interlayer is interactively depicted in the Petrel software, and the characterization results are incorporated into the model of the random distribution interlayer, as shown in Figure 8.

Through the above method, the final three-dimensional model of the interlayer is obtained. The model not only reflects the distribution law of the randomly distributed interlayer, but also combines the geological personnel's understanding of the stable distribution interlayer.

\section{Test and Analysis of Characterization Results}

Through stochastic simulation, several risk scenario models of the model are obtained, and the final lithofacies model is obtained by combining the model 


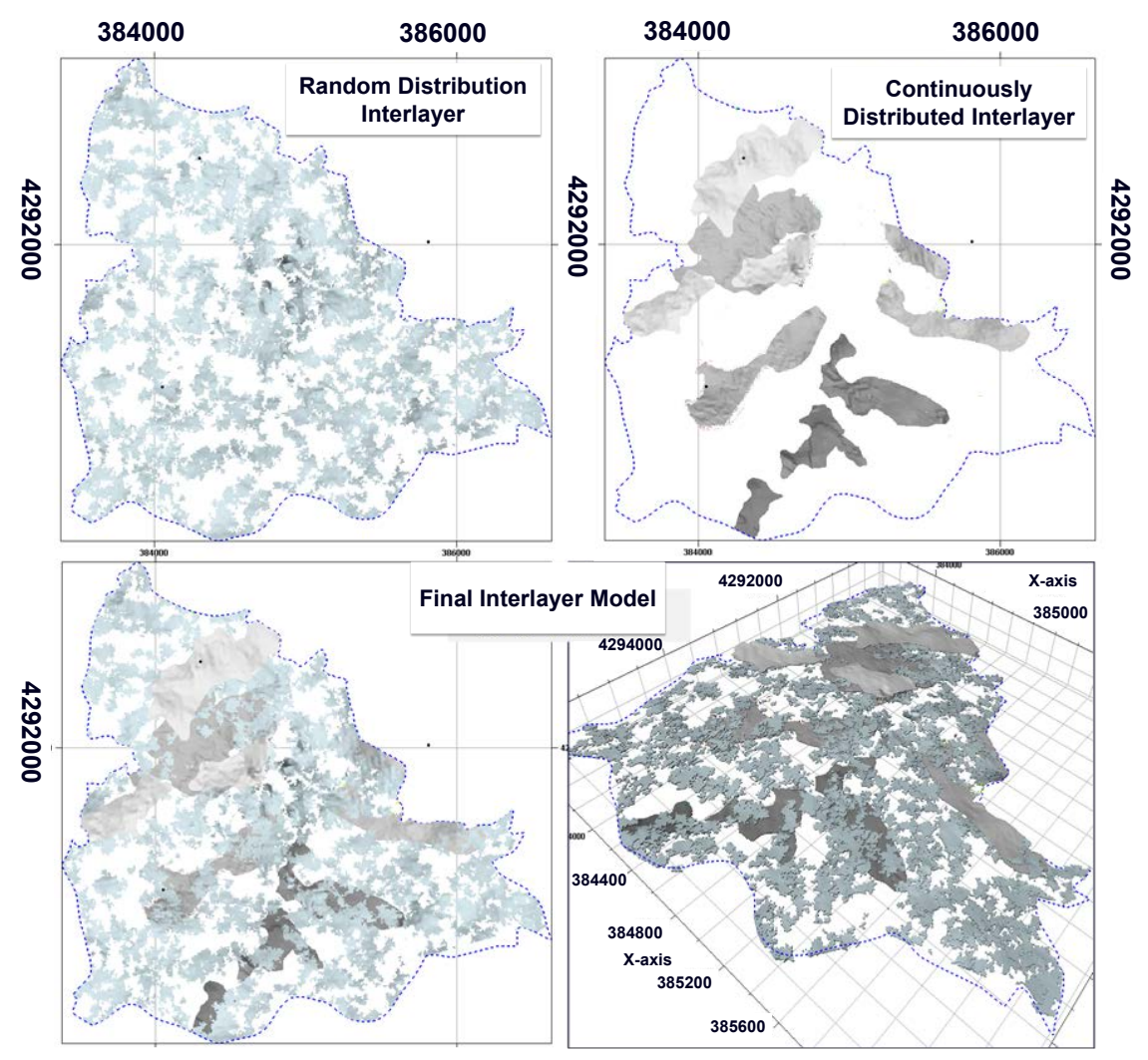

Figure 8. The final interlayers model of Um7 sand.

with the stable distribution interlayer. On this basis, the facies-controlled physical properties are modeled. In order to verify the accuracy of the results, the final model is verified by reservoir numerical simulation, and the interlayer model which is most in line with production performance is selected as the final interlayer model. The reservoir numerical simulation results of the final interlayer model show that the fitting results of 12 production wells in Um7 sand body are good, as shown in Figure 9.

Compared with the previous interlayer models, the model in this study pays more attention to the diversity of interlayer morphology. In previous models, the description of interlayers are too stable based on the results of well-to-well comparison and tracking, which results in the strong shielding effect of interlayers on bottom water coning; while in other models, only data analysis method is used to simulate interlayers, and the distribution of interlayers are too dispersed to play an effective shielding role.

This study fully considers the characteristics of many types and complex distribution of interlayer in meandering river sand bodies. Firstly, the interlayers are classified according to the lithology and sedimentary origin of interlayers. Based on this mode, the interlayer are further classified as stable interlayer and randomly distributed interlayer according to their morphology. The distribution characteristics of the two types of interlayer are characterized by the well-to-well comparison method and data analysis method respectively. 


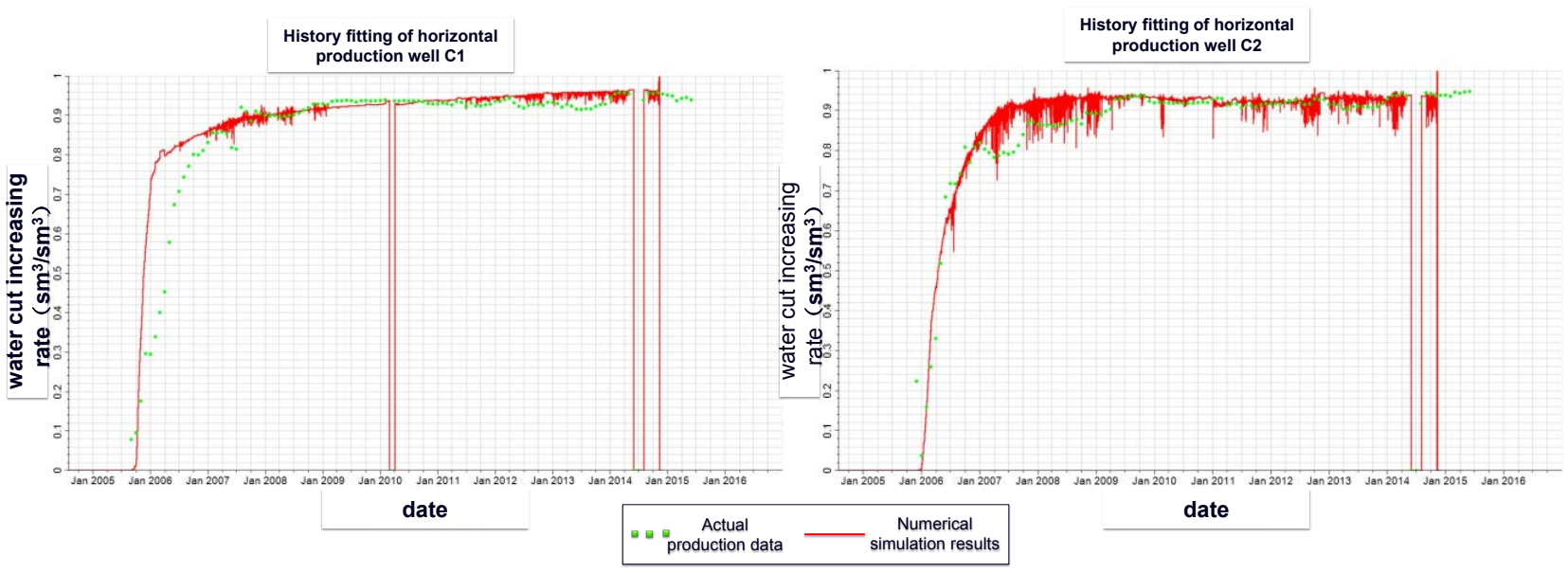

Figure 9. Use the numerical reservoir simulation to Test the final model.

This study shows the distribution characteristics of real underground interlayer more precisely, and the three-dimensional interlayer model better reflects the influence of interlayer on horizontal well production. The model is applied to reservoir numerical simulation, which is in good agreement with development performance.

\section{Conclusion}

In the sand body of the meandering river complex channel, the channel cuts frequently at different stages, which results in the complex distribution of interlayer in the sand body. Before the interlayer is depicted, it is necessary to identify different types of interlayer, and to establish the recognition pattern of different types of interlayer. The recognition pattern is used to identify and compare the interlayer in the whole area. For the interlayer with good continuity, it is suggested to compare and trace the interlayer with seismic data and logging data, and to embody the results in the model by interactive method. For the dispersed interlayer, data analysis method can be used to understand the distribution of interlayer, so as to guide the three-dimensional simulation of interlayer. In the production process of horizontal wells, the dynamic image of interlayer is large. Through the interlayer characterization method of this study, the distribution of interlayers with different distribution characteristics in reservoirs can be more truly reflected. The model not only reflects the distribution law of stochastic interlayers, but also combines the knowledge of geologists on stable interlayers, which makes up for the shortcomings of previous studies in describing interlayer.

\section{Conflicts of Interest}

The authors declare no conflicts of interest regarding the publication of this paper.

\section{References}

[1] Qiu, Y. (1996) The Methodology of Petroleum Development Geology (I). Petroleum 
Exploration and Development, 23, 43-47.

[2] Zhang, H. (1999) Petroleum Geology. Petroleum Industry Publishing House, Beijing.

[3] Zhao, H., Chen, Y., Tang. B., Lin, H., Liu, Y. and Zhang, Y. (2011) Heterogeneity of Chang 2 Reservoir in Dingbian Area, Ordos Basin. Lithologic Reservoirs, 23, 70-74.

[4] Mao, Z. (2003) Controlling Effects of Poor Permeable Layers upon Accumulation and Distribution of Hydrocarbon in Inhomogeneous Sandstone Reservoir. Earth Science, 28, 196-200.

[5] Gao, C., Sun, B., Sun, J., Cao, C., Wang, Y. and Yan, X. (2014) Characteristics of Low Permeability Reservoir of Chang 2 Reservoir in Xirengou Area, Ordos Basin. Lithologic Reservoirs, 26, 80-85.

[6] Du, Q., Chen, Y. and Hou, J. (2006) Control of Interlayer on the Distribution of Remaining Oil in Thick Reservoirs of Shengtuo Oilfield. Journal of Oil and Gas Technology, 28, 111-114.

[7] Chen, C. and Sun, Y. (2003) The Distribution Patterns of the Interlayers within Thick Pays and Their Impact on Recovery Efficiency. Petroleum Geology \& Oilfield Development in Daqing, 22, 24-27.

[8] Li, H., Li, X., Zhao, L. and Li, J. (2009) Developing Strategy of Interlayer Gas Reservoir with Horizontal Well. Oil Drilling \& Production Technology, 3, 96-99.

[9] Cui, J., Li, H., Feng, J., Liu, C. and Ju, Y. (2013) Barrier-Beds and Inter-Beds Characteristics and Their Effects on Remaining Oil Distribution in Braided River Reservoirs: A Case Study of the Ng IV Oil Unit in Shallow North Gaoshangpu Oilfield. Special Oil \& Gas Reservoirs, 20, 26-30.

[10] Dang, S., Yan, J., Feng, X., Qin, R. and Wang, W. (2015) Interlayer Research Application in Horizontal Well Development of Thick Bottom Water Reservoir-A Case of Massive sand in Caofeidian 11-6 Oilfield. Petroleum Geology and Recovery Efficiency, 5, 63-67.

[11] Wang, W., Guo, J., Li, B. and Zhu, M. (2016) Study on Conglomerate Interlayer of Guantao Formation and Subdivision Development Practices of Horizontal Wells. Reservoir Evaluation and Development, 6, 5-8.

[12] Yan, Y. and Duan, T. (2008) Identification and Inter-Well Prediction of Interbeds in Thick Oil Layer. Lithologic Reservoirs, 20, 127-131.

[13] Shu, Q. (2006) Interlayer Characterization of Fluvial Reservoir in Guantao Formation of Gudao Oilfield. Acta Petrolei Sinica, 7, 100-103.

[14] Lin, B., Dai, J., Ji, G. and Feng, J. (2008) Stochastic Modeling Study on Interlayers in 9-1 Layer, Segment 2 of Shahejie Formation, Tuo 7 Fault Block, Shengtuo Oilfield. Journal of Southwest Petroleum University (Science \& Technology Edition), 30, 11-14.

[15] Liu, C., Zhang, Y. and Shan, J. (2006) Genetic Mechanism and Distribution Features of Barriers and Baffles in Sandstone Reservoir. Natural Gas Industry, 26, 15-17.

[16] Wang, J., Xu, S. and Zhong, W. (2010) Origin and Distribution of the Interlayer in Fluvial Reservoir. Geological Science and Technology Information, 29, 84-88.

[17] Wang, Y. (2011) Accurate Characterization of Fluvial Facies Interbed and Its Control on Remaining Oil. Journal of Oil and Gas Technology, 33, 43-47.

[18] Zhang, S., Zhang, C., Yin, H., et al. (2000) Distribution of the Interbeds in the 2nd Oil Formation of the He-3 Member of the Shuanghe Oil Field, Henan. Sedimentary Geology and Tethyan Geology, 20, 71-78. 
[19] Zhang, G., Hou, J. and Wu, X. (2010) Modeling of Inner Interlayer Prediction in Thick Oil Layer-With Velasquez Oilfield as an Example. Science \& Technology Review, 28, 56-59.

[20] Zhao, H. (1985) Continuity of Intercalated Beds in Channel Sandstones. Petroleum Geology \& Oilfield Development in Daqing, 4, 1-11.

[21] Wu, S., Yue, D., Liu, J., Shu, Q., Fan, E. and Li, Y. (2008) Research on Hierarchical Modeling of Underground Ancient Channel Reservoir Structure. Science in China (Series D: Earth Sciences), 38, 111-121.

[22] Zhang, C., Zhou, H., Li, L., Shi, D., Liu, Z. and Hou, G. (2001) Modern Sediment Research in the Juzhang River. Bulletin of Mineralogy Petrology and Geochemistry, 20, 176-182.

[23] Lin, C., Hou, L. and Dong, C. (1997) Geostatistics Applied to the Identification of Interbeds, with Sha-3 Member of Western Liaohe Depression Taken as an Example. Experimental Petroleum Geology, 19, 245-251.

[24] Feng, W. (2009) Quantitative Recognition of Interbed Types in Fluvial Reservoirs. Petroleum Geology and Recovery Efficiency, 16, 40-43.

[25] Si, L. (2008) Geological Modeling for Point Bar of Meandering River and Its Application in Horizontal Well. Lithologic Reservoirs, 20, 104-108. 